\title{
High-Precision Coulometric Titrations of Boric Acid
}

\author{
George Marinenko and Charles E. Champion* \\ Institute for Materials Research, National Bureau of Standards, Washington, D.C. 20234
}

(June 4, 1971)

\begin{abstract}
An absolute method was developed for the determination of boric acid by coulometric titrimetry. The precision of the method, expressed as the standard deviation of a single determination is 0.0033 percent. Changes in the investigated titration parameters produced no significant effects on the titration results. Indications are that within the uncertainty of measurements the method is bias free.
\end{abstract}

Key words: Accurate analysis; boric acid; coulometric titration; high-precision acidimetry; high precision coulometry.

\section{Introduction}

The National Bureau of Standards conducts a great deal of research towards establishment of absolute standards in all areas of the measurement field. One area which enables analytical quantification of chemical property on the absolute basis is coulometry. For this reason, over a number of years, an intense effort has been made to develop methods for precise analysis and to test the accuracy of these methods $[1-5] .{ }^{1}$ This paper is one of a series of articles on the development of precise coulometric methods and their application to characterization of high purity standard reference materials (SRMs).

The expanding use of boron and its compounds in nuclear technology and the NBS program concerned with the issuance of an SRM for neutron flux monitoring necessitated the development of a method for the precise and accurate determination of this element. The most widely used method for the determination of milligram amounts of boron involves titration of boric acid in the presence of a polyol [6], usually mannitol. However, this method is somewhat empirical in nature, particularly with respect to the amount of polyol required for titration and moreover, is generally precise to only a few parts per thousand. Le Duigou and Lauer recently reported a procedure for the coulometric determination of boron [7]. Their precision for 150-mg samples of boric acid was on the order of 0.02 percent. Thus, the method appeared promising from the standpoint of precision, but the disturbing fact is that these authors found a discrepancy of 0.1 percent between the coulometric value and the value obtained by conventional acidimetric titration. Referring to the coulo-

*Present address: Methods Research and Technical Service Division, Eastman Kodak, Rochester, New York 14603.

1 Figures in brackets indicate literature references at the end of this paper. metric method, these authors concluded that further studies are necessary to improve its accuracy. This conclusion alone was sufficient to arouse our interest in the coulometric behavior of the system, particularly from the standpoint of possible sources of error which apparently have not been ruled out in the coulometric investigations of Le Duigou and Lauer.

We therefore undertook investigation of the effects of various titration parameters on the coulometric analysis of boric acid complexed with mannitol.

\section{General Considerations}

The principal material investigated was boric acid, SRM \#951. The analysis of this material by emission spectroscopy indicated that total metallic impurities did not exceed a few parts per million.

Reagent grades of $\mathrm{KCl}$ and mannitol were used for the preparation of the supporting electrolyte. Titrations of small amounts of HCl (20-30 $\mu \mathrm{eq})$ showed that the neutrality point of $1 \mathrm{M} \mathrm{KCl}$ containing mannitol is at $\mathrm{pH}=6.98$. Consequently, in all experiments, small amounts of $\mathrm{HCl}$ were added to the electrolyte to facilitate removal of $\mathrm{CO}_{2}$ by nitrogen purging, and the electrolyte was pretitrated to neutrality before the addition of the investigated boric acid sample.

\section{Apparatus and Procedure}

\subsection{Apparatus}

The instrumentation, apparatus, and acidimetric procedure used in our laboratory have been described previously [8]. The coulometric cell used in these analyses is shown in figure 1. The constant-current and timing facility enables measurement of charge passed through the cell with an accuracy of a few parts in 


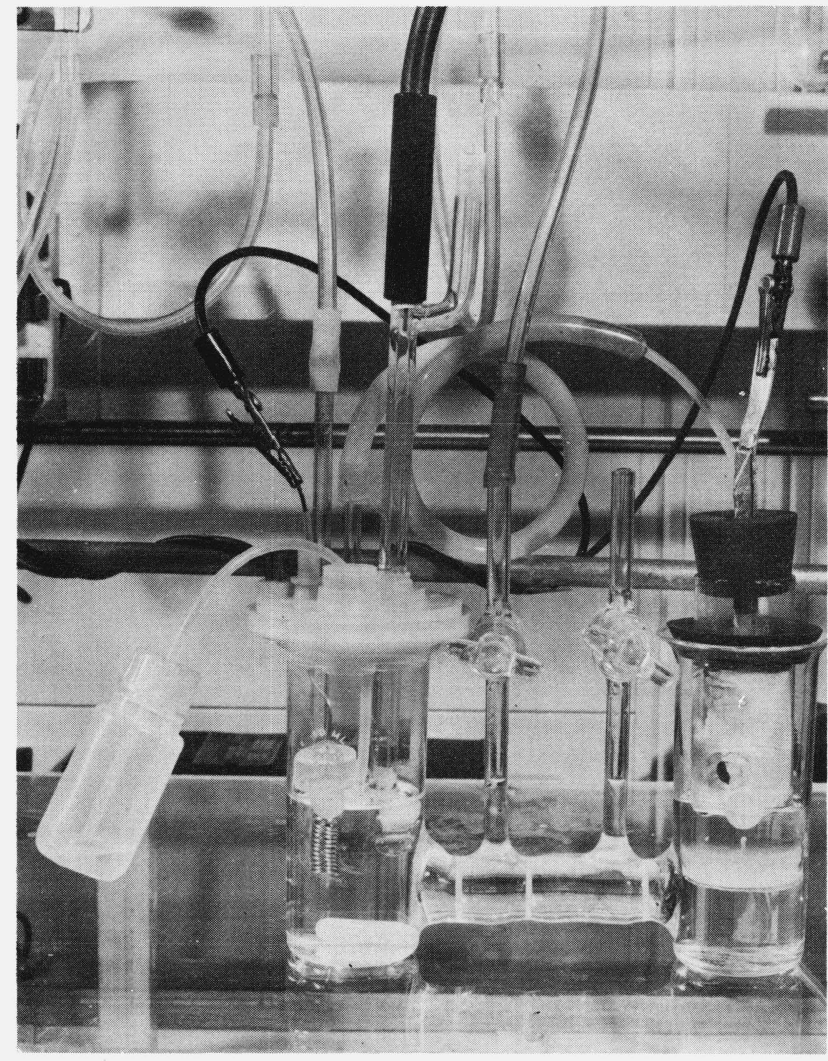

FiguRE 1. Coulometric titration cell for boric acid analysis.

106. The mass of samples is measured with an accuracy of $0.003 \mathrm{mg}$ by substitution weighing on a $20-\mathrm{g}$ capacity microbalance. The end point of titration is determined potentiometrically using a $\mathrm{pH}$ meter and a glass-calomel combination electrode. The readability of the $\mathrm{pH}$ meter is $0.001 \mathrm{pH}$ unit. Although the accuracy of the $\mathrm{pH}$ measurement is not very significant since a differential procedure is used and the inflection point is taken as the equivalence point, the $\mathrm{pH}$ meter was regularly standardized against NBS $\mathrm{pH}$ 6.865 phosphate buffer (SRM \#186Ic and SRM \# 186IIb).

\subsection{Procedure}

In our previous procedures, the acid was titrated at high current (100 mA) for a precalculated period of time to bring the system very near to the end point, followed by the passage of small charge increments at lower current. After passage of each charge increment, $\mathrm{pH}$ was measured and the inflection point on the potentiometric curve was established graphically using a $\Delta \mathrm{pH} / \Delta C$ versus $\mathrm{C}$ plot. In such a procedure, one titrates significantly beyond the inflection point. The final $\mathrm{pH}$ change, due to rinsing of cell walls, cell cover and intermediate compartments, takes place on that portion of the potentiometric curve, the slope of which is significantly lower than $(\Delta \mathrm{pH} / \Delta C)_{\max }$. Thus, the estimate of the correction due to final rinsing is not as accurate as it could be if it were measured in the region close to $(\Delta \mathrm{pH} / \Delta C)_{\max }$. However, in such a procedure, one cannot stop the titration in the immediate vicinity of the inflection point without jeopardizing the accuracy of the evaluation of $(\Delta \mathrm{pH} / \Delta C)_{\max }$. To satisfy both of these conditions, the titration procedure was modified.

It was found in a few preliminary experiments that the boric acid used was very close to stoichiometric $\mathrm{H}_{3} \mathrm{BO}_{3}$. Consequently 100.00 percent of the precalculated number of coulombs, necessary to reduce all of the hydrogen ion which is delivered into the cell with the boric acid sample, was passed through the cell. The cell walls, top and intermediate compartments were rinsed until no significant change in $\mathrm{pH}$ (within 0.003 $\mathrm{pH}$ units) was observed, and the final $\mathrm{pH}$ of the solution was recorded. Since the acid was close to stoichiometric $\mathrm{H}_{3} \mathrm{BO}_{3}$, this $\mathrm{pH}$ measurement was made in the $(\Delta \mathrm{pH} / \Delta C)_{\max }$ region and thus in the region of maximum sensitivity. To determine the difference (in coulombs) between the $\mathrm{pH}$ at this final rinse point and the $\mathrm{pH}$ at $(\Delta \mathrm{pH} / \Delta C)_{\max }$, a small amount of hydrochloric acid $(10-20 \mu \mathrm{eq})$ was added to the cell and the regenerated boric acid was retitrated differentially to establish $\mathrm{pH}$ at $(\Delta \mathrm{pH} / \Delta C)_{\max }$. This process can be repeated several times to improve the evaluation of the inflection point (9). In practice, then, a correction of a few thousandths of a percent is applied at the end of the titration for the difference between the final $\mathrm{pH}$ and the $\mathrm{pH}$ at the inflection point.

The procedure can be clarified by considering a specific example. A sample of boric acid, contained in a polyethylene boat and weighing $0.599207 \mathrm{~g}$ (vacuum corrected weight), was delivered into the cathode compartment of the coulometric cell containing $100 \mathrm{ml}$ of 1M KCl-0.75M mannitol supporting electrolyte which had been previously pretitrated to neutrality point.

After passage of the precalculated charge of 935.204 $\mathrm{C}$ at $101.7840 \mathrm{~mA}$, the current was interrupted, the intermediate cell compartments were rinsed, and a final $\mathrm{pH}$ reading of 8.234 was observed. A few drops of $0.1 \mathrm{~N} \mathrm{HCl}$ were added to the cathode compartment whereupon the $\mathrm{pH}$ of solution dropped to 7.567 . Equal charge increments $(0.100 \mathrm{C})$ were passed through the cell at $10.178 \mathrm{~mA}$ and the $\mathrm{pH}$ was measured following passage of each increment. The data obtained are shown in table 1 and figure 2 .

The inflection point occurred at $\mathrm{pH}=8.095$ (point $\mathrm{A}$ on the graph). The $\mathrm{pH}$ at the completion of the passage of charge through the cell at high current was 8.234 (point B on the graph), corresponding to an overtitration of $0.178 \mathrm{C}$. Thus, it is necessary to correct the total charge by $-0.178 \mathrm{C}$, and the number of coulombs equivalent to the delivered sample of boric acid is 935.026 C. By Faraday's law this corresponds to 9.69069 meq of acid or the weight of boric acid of $0.599205 \mathrm{~g}$. Since $0.599207 \mathrm{~g}$ of the acid was weighed out, the assay of the material found in this titration is 99.9997 weight percent $\mathrm{H}_{3} \mathrm{BO}_{3}$.

In an earlier communication the error which resulted from the difference between the inflection point and the equivalence point in coulometric titration of boric acid was evaluated [9]. It was found that when $c K_{a}$ is $10^{-9}$, the error is 0.003 percent, and for larger $c K_{a}$ it is 


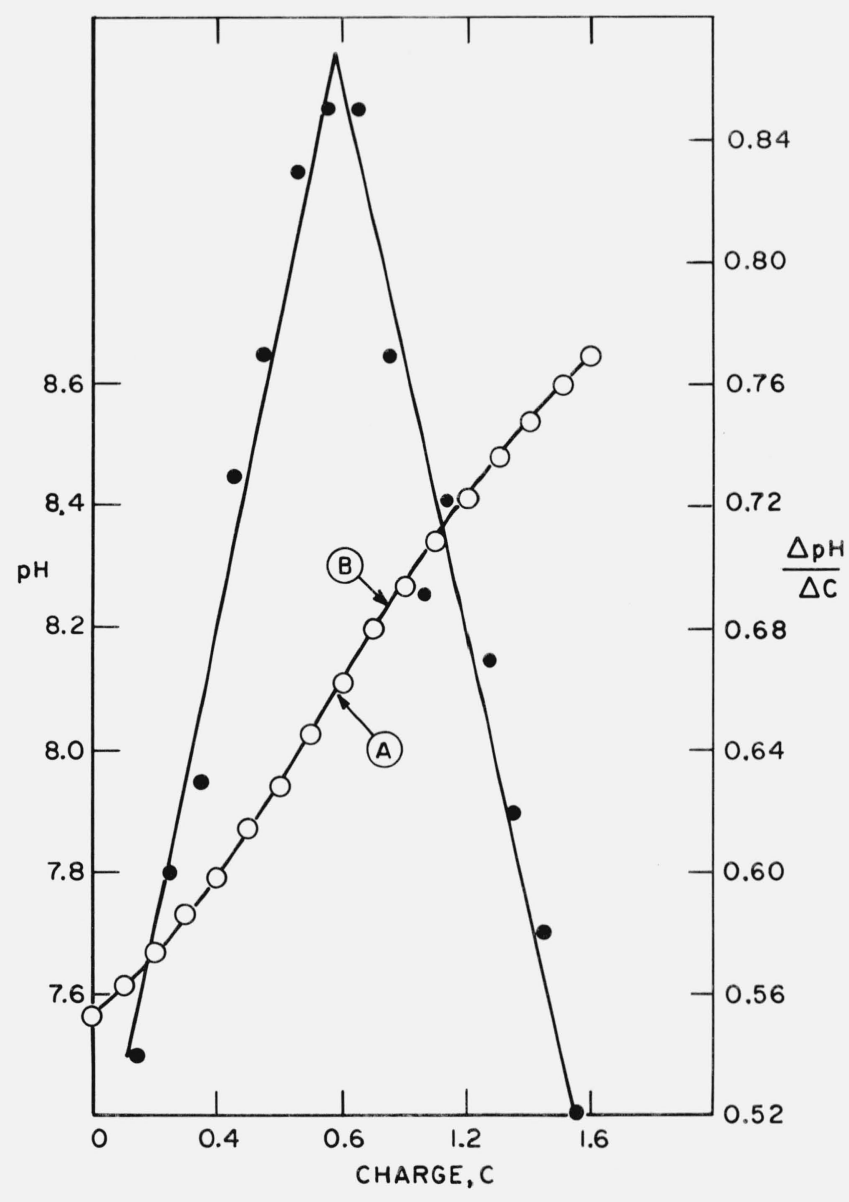

Figure 2. Determination of the end-point in coulometric titration of boric acid.

- points for $\mathrm{pH}=f(\mathrm{C})$

- points for $\Delta \mathrm{pH} / \Delta C=f(C)$

$A$ - inflection point $(\Delta \mathrm{pH} \mid \Delta C)_{\text {max }}$

$\mathrm{B}-$ final $\mathrm{pH}$ of titration. correspondingly smaller, as predicted by the Roller equation [10]. All of the subsequent work was conducted under the condition when $c K_{a} \gg 10^{-9}$ and thus the error due to this source is negligible.

\section{Experimental Variables}

It was pointed out above that the investigation of Le Duigou and Lauer [7] raised the question as to the accuracy of coulometric titration of boric acid. There are two ways of examining this problem. First, and the simplest, would be to titrate boric acid of known stoichiometry. Unfortunately materials of stoichiometry known to a thousandth of a percent are not available. The second method would be an indirect one, involving a study of all known sources of possible systematic error. Of necessity, the second path was followed.

To determine the nature of the effect of various titration parameters, each of them was varied over the desired range and the observed effects are reported in the following discussion.

The accuracy of coulometric acidimetry conducted in $1 \mathrm{M} \mathrm{KCl}$ medium has been treated earlier $[1,8,11]$.

In titrations of boric acid, however, the supporting electrolyte, in addition to potassium chloride, must also contain mannitol. It was therefore necessary to determine if the mannitol has any effect on the electrochemical reaction at the platinum cathode. To investigate the possible interference of mannitol in the coulometric reaction, $\mathrm{HCl}$ solution, single crystal oxalic acid dihydrate, and acid potassium phthalate. respectively, were analyzed coulometrically in $1 \mathrm{M} \mathrm{KCl}$ both with and without mannitol. This choice of acids was made to cover a range of $p K_{a}$ values which would include the $p K_{a}$ of mannitoboric acid (in $0.75 \mathrm{M}$ mannitol, the apparent $K_{a}$ of boric acid is $4.17 \times 10^{-5}$ ).

Hydrochloric acid solution was made by dilution of reagent grade concentrated acid in a one-liter volumetric flask to approximately $1 \mathrm{M}$ concentration. The flask was stoppered with serum rubber septum and kept between uses in a 100 percent relative humidity atmosphere. Samples of this solution were aliquoted for analysis by weight using the disposable syringe and platinum hypodermic needle as weight buret. The rubber septum, covering the $\mathrm{HCl}$ solution, was pierced by the hypodermic needle and the required volume of solution was withdrawn by the earlier described procedure [12].

Oxalic acid dihydrate was single crystal material, grown in a mixed acetone-water bath by the temperature dropping technique [13]. It is the same material which was used in the determination of the electrochemical equivalent and the faraday [8].

Potassium hydrogen phthalate was NBS SRM \#84h. It was assayed coulometrically in $1 \mathrm{M} \mathrm{KCl}$ by Paabo [14]. The data obtained by Paabo is compared with our data obtained in mannitol containing electrolyte. The results of the analyses of these acids are summarized in table 2, and will be discussed in the appropriate section of this paper. 
TABLE 2. Effect of mannitol on electrochemical reduction of $\mathrm{H}^{+}$at platinum cathode

\begin{tabular}{|c|c|c|}
\hline Acid & $1 \mathrm{M} \mathrm{KCl}$ & $1 \mathrm{M} \underset{\text { Mannitol }}{\mathrm{KCl}+0.75 \mathrm{M}}$ \\
\hline Hydrochloric acid & $\begin{array}{l}1.05135 \mathrm{meq} / \mathrm{g} \\
1.05131 \\
1.05121 \\
1.05138 \\
1.05130\end{array}$ & $\begin{array}{l}1.05141 \mathrm{meq} / \mathrm{g} \\
1.05139 \\
1.05132 \\
1.05128 \\
1.05141\end{array}$ \\
\hline \multirow[t]{2}{*}{ Average } & $1.05131 \mathrm{meq} / \mathrm{g}$ & $1.05136 \mathrm{meq} / \mathrm{g}$ \\
\hline & $s=0.00007$ & $s=0.00006$ \\
\hline $\begin{array}{l}\text { Oxalic acid } \\
\text { dihydrate }^{\text {a }}\end{array}$ & $\begin{array}{l}99.985 \text { percent } \\
99.985 \\
99.983 \\
99.987 \\
99.987 \\
99.983\end{array}$ & $\begin{array}{l}\text { b } 99.972 \text { percent } \\
99.987 \\
99.988 \\
99.991 \\
99.986\end{array}$ \\
\hline \multirow[t]{2}{*}{ Average } & 99.985 percent & 99.988 percent \\
\hline & $s=0.001$ & $s=0.002$ \\
\hline $\begin{array}{l}\text { Potassium acid } \\
\text { phthalate, NBS } \\
\text { Standard } \\
\text { Reference } \\
\text { Material 84h }\end{array}$ & & $\begin{array}{l}99.995 \text { percent } \\
99.996 \\
99.989 \\
100.005 \\
99.999 \\
100.001\end{array}$ \\
\hline \multirow[t]{2}{*}{ Average } & c 99.992 & 99.998 percent \\
\hline & $s=0.006$ & $s=0.006$ \\
\hline
\end{tabular}

a Single crystal chips grown by J. L. Torgesen and J. Strassburger [11].

6. This result is an outlier and thus excluded from consideration [F. E. Grubbs. Tech nometrics. 11,1 (1969)].

The assay is the mean value of 17 titrations obtained coulometrically during the analysi of the material for NBS certification by M. Paabo [14].

The effect of mannitol on the strength of boric acid has been investigated quite extensively [15-22]. Much of this work can be summarized from the analytical standpoint as follows: (a) boric acid becomes stronger as the mannitol concentration increases; (b) in concentrated solutions, anomalous conductance values indicate association; (c) electrolytes in solution affect the boric acid hydrolytic equilibrium. Thus, as the concentration of mannitol increases, the end point $\mathrm{pH}$ of boric acid titration decreases, and the slope of the titration curve increases. However, it has not been established whether or not this has an influence on the stoichiometry of acidimetric reaction and consequently on the titration results.

Accordingly, a number of samples of boric acid were analyzed in the following electrolytes: $1 \mathrm{M} \mathrm{KCl}-0.25 \mathrm{M}$ mannitol; $1 \mathrm{M} \mathrm{KCl-0.75M} \mathrm{mannitol;} 1 \mathrm{M} \mathrm{KCl-1.05M}$ mannitol (saturated). The data are shown in figure 3.

In the investigation of the mannitol effect, the boric acid sample size was also varied as shown in the same figure.

Most of the analyses of boric acid were performed in $1 \mathrm{M} \mathrm{KCl-0.75M}$ mannitol electrolyte, and consequently much more extensive data were obtained on sample size dependence of the assay in this medium. These data are summarized in table 3 .

Study of the behavior of the SRM boric acid which was used throughout this work indicates that this material is somewhat deficient in water. It was apparently prepared under conditions which resulted in the formation of small amounts of $\mathrm{B}_{2} \mathrm{O}_{3}$. This conclusion is supported by the following evidence. Samples weighed directly from the original boric acid containers and permitted to sit in the room at 28 percent relative humidity for 30 minutes gained weight, as illustrated in table 4 . The mean value of the percentage weight gains for six samples, in the indicated period of time, was found to be 0.008 percent. Analysis of the material after 30 -min exposure to 28 percent relative humidity resulted in an assay of 100.005 percent, indicating that this treatment is still not quite sufficient to produce stoichiometric $\mathrm{H}_{3} \mathrm{BO}_{3}$.

Additional information on the effect of the relative humidity of the environment on the stoichiometry of $\mathrm{B}_{2} \mathrm{O}_{3}-\mathrm{H}_{2} \mathrm{O}$ system at $25{ }^{\circ} \mathrm{C}$ was obtained in controlled humidity experiments. Boric acid was initially exposed to room atmosphere (approx. 34\% RH) for several hours, in the course of which the material absorbed water and approached stoichiometric composition. Subsequently, boric acid was placed in controlled humidity environments. After at least a four-day exposure to a controlled atmosphere with an occasional mixing of the crystals, samples were weighed out for analysis. The results of these analyses are shown in figure 4 . It can be seen that in the 0 to 60 percent relative humidity range, the assay of boric acid remains constant and close to stoichiometric $\mathrm{H}_{3} \mathrm{BO}_{3}$. Beyond 60 percent relative humidity, additional water is sorbed by boric acid, reaching a value of 0.02 percent (referred to the weight of stoichiometric boric acid) at 90 percent relative humidity.

It is thus concluded that exposure of this lot of boric acid to humid atmosphere is beneficial, in fact necessary if one wishes to insure that stoichiometric $\mathrm{H}_{3} \mathrm{BO}_{3}$ composition was achieved. Subsequently, the material is stable and can be stored at any humidity below $\sim 60$ percent. Considering even drastic environmental conditions, such as variation of humidity between 0 and 90

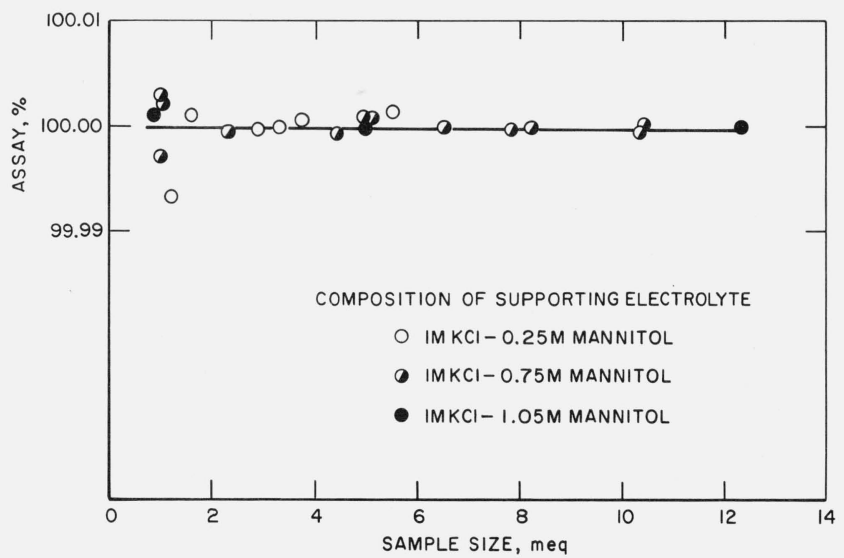

Figure 3. Effect of mannitol concentration and sample size on the coulometric titrations of boric acid. 
TABLE 3. Analysis of boric acid in $1 \mathrm{M} \mathrm{KCl-0.75M}$ mannitol

\begin{tabular}{|c|c|c|c|c|c|c|c|}
\hline $\begin{array}{l}\text { Sample } \\
\text { number }\end{array}$ & $\begin{array}{l}\text { Sample } \\
\text { size } \\
(\mathrm{mg})\end{array}$ & Assay, $\%$ & Residuals & $\begin{array}{l}\text { Sample } \\
\text { number }\end{array}$ & $\begin{array}{c}\text { Sample } \\
\text { size } \\
(\mathrm{mg})\end{array}$ & Assay, \% & Residuals \\
\hline 1 & 271 & 99.9992 & -0.0001 & 28 & 200 & 99.9993 & 0.0000 \\
\hline 2 & 304 & 100.0018 & .0025 & 29 & 200 & 99.9990 & -.0003 \\
\hline 3 & 304 & 100.0010 & .0017 & 30 & 200 & 100.0028 & .0035 \\
\hline 4 & 639 & 99.9997 & .0004 & 31 & 200 & 100.0005 & .0012 \\
\hline 5 & 403 & 99.9993 & .0000 & 32 & 200 & 100.0042 & .0049 \\
\hline 6 & 640 & 100.0010 & .0017 & 33 & 200 & 100.0020 & .0027 \\
\hline 7 & 143 & 99.9988 & -.0005 & 34 & 200 & 99.9955 & -.0038 \\
\hline 8 & 481 & 99.9990 & -.0003 & 35 & 200 & 99.9975 & -.0018 \\
\hline 9 & 670 & 100.0038 & .0045 & 36 & 200 & 100.0037 & .0044 \\
\hline 10 & 712 & 100.0030 & .0036 & 37 & 200 & 100.0008 & .0015 \\
\hline 11 & 642 & 99.9973 & -.0020 & 38 & 200 & 99.9978 & -.0015 \\
\hline 12 & 500 & 99.9989 & -.0004 & 39 & 200 & 99.9990 & -.0003 \\
\hline 13 & 600 & 99.9889 & -.0104 & 40 & 200 & 99.9941 & -.0052 \\
\hline 14 & 600 & 99.9999 & .0006 & 41 & 200 & 99.9983 & -.0010 \\
\hline 15 & 600 & 100.0022 & .0029 & 42 & 200 & 99.9992 & -.0001 \\
\hline 16 & 600 & 100.0024 & .0031 & 43 & 200 & 99.9998 & .0005 \\
\hline 17 & 600 & 99.9978 & -.0015 & 44 & 200 & 100.0024 & .0031 \\
\hline 18 & 600 & 99.9997 & .0004 & 45 & 200 & 99.9987 & -.0006 \\
\hline 19 & 600 & 100.0010 & .0017 & 46 & 200 & 100.0009 & .0016 \\
\hline 20 & 600 & 99.9983 & -.0010 & 47 & 200 & 100.0002 & .0009 \\
\hline 21 & 600 & 99.9964 & -.0029 & 48 & 200 & 100.0012 & .0019 \\
\hline 22 & 600 & 100.0032 & .0039 & 49 & 200 & 99.9961 & -.0032 \\
\hline 23 & 600 & 99.9910 & -.0083 & 50 & 200 & 100.0042 & -.0049 \\
\hline 24 & 600 & 99.9975 & -.0018 & 51 & 200 & 100.0007 & .0014 \\
\hline 25 & 200 & 100.0004 & .0011 & 52 & 200 & 99.9973 & -.0020 \\
\hline 26 & 200 & 99.9896 & -.0097 & 53 & 200 & 100.0025 & .0032 \\
\hline 27 & 200 & 99.9960 & -.0033 & 54 & 200 & 100.0006 & .0013 \\
\hline
\end{tabular}

percent, the material changes its stoichiometry by only 0.020 percent. This probably occurs due to adsorption of water on polycrystalline boric acid.

In view of initial decrease of assay of this material when it was exposed to moderate humidity environment, its stability up to ca. 60 percent R.H., and further decrease beyond this humidity, we conclude that the material equilibrated at 35 percent relative humidity is very close to stoichiometric $\mathrm{H}_{3} \mathrm{BO}_{3}$ composition so far as $\mathrm{H}_{2} \mathrm{O}-\mathrm{B}_{2} \mathrm{O}_{3}$ equilibrium is concerned.

Though accurate acidimetric assay value has been obtained for the investigated $\mathrm{H}_{3} \mathrm{BO}_{3}$, in many instances

TABLE 4. Adsorption of water by boric acid

\begin{tabular}{c|l|l|r|r}
\hline \hline $\begin{array}{c}\text { Sample } \\
\text { number }\end{array}$ & $\begin{array}{c}\text { Initial wt } \\
\text { of } \mathrm{H}_{3} \mathrm{BO}_{3}\end{array}$ & $\begin{array}{c}\text { Wt of } \mathrm{H}_{3} \mathrm{BO}_{3} \\
\text { after 30-min } \\
\text { exposure to } \\
28 \% \mathrm{RH}\end{array}$ & $\Delta W \times 10^{6} \mathrm{~g}$ & $\begin{array}{c}\text { Change in } \\
\text { weight, percent }\end{array}$ \\
\hline & & & & +0.010 \\
1 & $1.351348 \mathrm{~g}$ & $1.351484 \mathrm{~g}$ & +136 & +.004 \\
2 & 1.340345 & 1.340394 & +49 & +.011 \\
3 & 0.934555 & 0.934655 & +100 & +.010 \\
4 & 1.685807 & 1.685968 & +161 & +.005 \\
5 & 2.249267 & 2.249379 & +112 & +.010 \\
6 & 1.343683 & 1.343823 & +140 & \\
& & & & Average +0.008 \\
\hline
\end{tabular}

the element of interest is boron. Since acidimetry is only an indirect method of assaying this material for boron, one must in fact prove the correspondence between the titratable $\mathrm{H}^{+}$and $\mathrm{B}$.

The presence of strong acids or metal borates could not be detected titrimetrically below a few hundredths

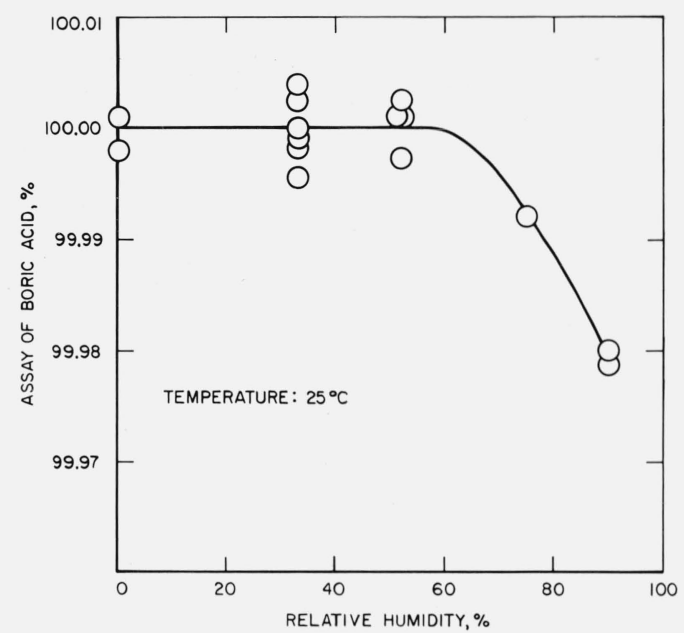

FIGURE 4. Effect of the humidity of the environment on the assay of boric acid. 
of a percent level. Spectrographic analysis revealed that the material is virtually free of metallic impurities (a few ppm level). Thus, it remained to be proven that the titrated hydrogen ion is contributed totally by the boric acid or to correct the acidimetric assay for the presence of the contaminating acid or metal borates.

To perform this task with a sensitivity greater than that indicated above (a few hundredths of a percent), advantage was taken of the ten-fold increase in solubility of $\mathrm{H}_{3} \mathrm{BO}_{3}$ between 0 and $100{ }^{\circ} \mathrm{C}$. Thus, the contaminating acid or salt could be preconcentrated into the aqueous phase by recrystallization in a sealed bomb and then the contaminating acid could be titrated coulometrically with a ten-fold greater "effective" sensitivity.

The $\mathrm{pH}$ measurements on the "extracted" aqueous phase indicated the presence of strong acid. Coulometric determinations of this strong acid show that $0.00055 \pm 0.00005$ percent of the titratable hydrogen ion in the original boric acid is furnished by strong acid, where the uncertainty figure represents the standard deviation of the mean of three determinations.

\section{Results}

The data presented in the previous section of the paper can now be analyzed to see if it can shed some light on the question of the existence or absence of significant effect of various titration parameters on the analytical results.

\subsection{Effect of Mannitol on Electrochemical Reduction of $\mathbf{H}^{+}$}

It was stated earlier that in order to establish whether mannitol affects the current efficiency of the electrochemical reaction

$$
\mathrm{H}^{+}+e \rightarrow 1 / 2 \mathrm{H}_{2}
$$

apart from its effect on boric acid titrimetry, three different acids were analyzed in $1 \mathrm{M} \mathrm{KCl}$ supporting electrolyte and in a mannitol containing electrolyte (table 2).

The precision of two sets of analysis of hydrochloric acid in the two electrolytes are comparable (standard deviations are 0.0064 and 0.0055 percent in $1 \mathrm{M} \mathrm{KCl}$ and in $1 \mathrm{M} \mathrm{KCl}+0.75 \mathrm{M}$ mannitol, respectively). On the basis of a Student's $t$-test the difference of the means of the two sets $(0.00005 \mathrm{meq} / \mathrm{g})$ is not significant even at the 10 percent level of significance [23].

On the basis of acid strength of the three acids in table 2, one would expect the precision of the determination of the end point to be the highest for $\mathrm{HCl}$ solution, and consequently the overall precision to be the highest for $\mathrm{HCl}$ titrations. However, the fact that this acid is aliquoted in the form of solution has an adverse effect on the material handling process and it apparently outweights the increased precision of the end point. Thus, no overall improvement of the precision of results (in fact, some deterioration of precision in comparison with oxalic acid) is observed. Similar dif- ficulties with handling $\mathrm{HCl}$ solutions were experienced earlier in this laboratory [1] and by other investigators [11].

The next weaker acid to be titrated in the two electrolytes was oxalic acid. It was already mentioned that the purity of this material was evaluated previously on the basis of impurity analysis [8]. Its purity is 99.9871 \pm 0.0015 percent, where the uncertainty figure represents an estimate of the 95 percent confidence limits.

The first titration result for the oxalic acid in mannitol containing electrolyte is an "outlier." The difference between this titration result and the combined mean is more than a factor of six greater than the pooled standard deviation. As such it is excluded from the mean of its own set and from all considerations of the effect of mannitol on coulometric acidimetry.

The two resulting means (with and without mannitol) do not differ significantly from each other and from the independently evaluated purity of the acid $(99.987 \%)$ at the 95 percent confidence level.

Similarly the consideration of the two titration sets for potassium acid phthalate revealed no significant difference.

Thus, even a pessimistic outlook would indicate that mannitol has no effect on coulometric acidimetry at 0.005 percent level. The absence of any significant interaction between these three acids and mannitol is indicated by the fact that the $\mathrm{pH}$ of the inflection points on the potentiometric titration curves, obtained with the use of the glass-saturated calomel electrode system, is virtually unaffected by the presence of mannitol. One can therefore conclude that under the experimental conditions employed in this work the reaction at the platinum cathode is unaffected by the presence of mannitol.

\subsection{Effect of Mannitol on Boric Acid Titrimetry}

The effect of mannitol on the results of analysis of boric acid was investigated in electrolytes containing $0.25,0.75$, and $1.05 \mathrm{M}$ mannitol. From the results in figure 3 it is apparent that these analyses show no systematic difference among the results obtained in the three media.

In regard to the magnitude of the inflection point, an electrolyte containing $1.05 \mathrm{M}$ mannitol is superior, however, its viscosity is rather high which presents some difficulties in forcing this solution through the fritted glass disks of the coulometric cell as well as in the homogenization of the solution during the course of anlysis. Hence, as a matter of convenience the next lower concentration $(0.75 \mathrm{M})$ of mannitol was used throughout subsequent work.

\subsection{Effect of Sample Size on Boric Acid Titrimetry}

As indicated in figure 3, boric acid sample size was varied along with concentration of mannitol. Examination of this graphical data shows no systematic effect of sample size on the assay. More extensive titration data obtained in $1 \mathrm{M} \mathrm{KCl}-0.75 \mathrm{M}$ mannitol electrolyte is shown in table 3. A least-square fit of this data to a 
linear equation relating assay to the sample size shows that the slope of the fitted curve is not significantly different from zero. (Any value of the slope computed by the method of least-squares is an order of magnitude lower than the standard deviation of this value.) Thus, there is no apparent sample size effect on the assay of boric acid within the investigated range. Earlier it was pointed out that boric acid of known purity is not available for evaluating the overall accuracy of the developed method. However, the absence of analytical bias due to composition of electrolyte and to sample size gives no reason to suspect the method of being inaccurate. As it is usually done, the precision of the method can be expressed as the standard deviation of a single determination. On the basis of data in table 3 , the standard deviation of a single determination is 0.0033 percent. This estimate of precision is consistent with the data of figure 3 and is of the same order as for other high-precision coulometric methods reported in the literature $[1-5,8,11$, $24,25]$.

Moreover, the analysis of titration data in table 3 in the sequence in which analyses were performed is shown in figure 5. It is apparent that the sequence of titration has no apparent systematic effect on the results.

\section{Discussion}

Colman and Rigdon [21] investigated the effects of various titration parameters such as the ratio of mannitol to boric acid, various cations, ionic strength and temperature on titration of aqueous solution of boric acid with $\mathrm{NaOH}$. They attribute the imprecision of the method of titration to a fixed $\mathrm{pH}$ as being caused by the variation of all these parameters. They point out that these variables can be adjusted so that $(\mathrm{pH})_{\text {equiv }}$ occurs in $6.3-9.2 \mathrm{pH}$ range and recommend at least 16:1 mole ratio of mannitol to boron.

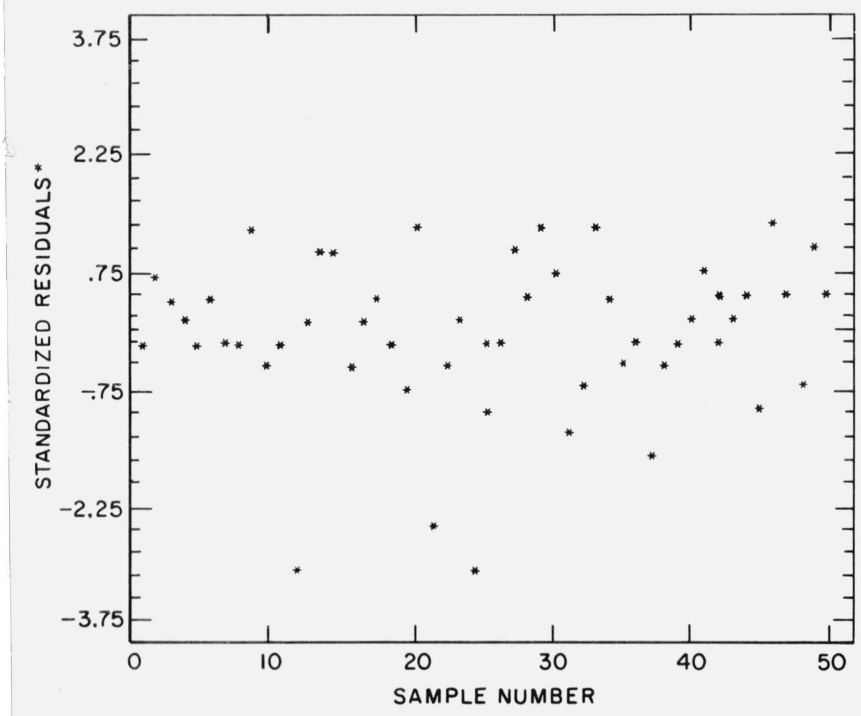

FigURE 5. Dependence of assay on titration sequence.

*Standardized residual represents the ratio of a residual to the standard deviation of a single determination.
This investigation and the investigations carried out earlier $[9,26]$ show that the unique behavior of this system can be attributed totally to variable $p K$ of boric acid in mannitol media, caused by the formation of mannitol-borate complex. All the other parameters (temperature, ionic strength, etc.) are merely reflected as changes in the dissociation constant of boric acid and the complexation equilibrium of borate with mannitol. Needless to say, then, if $p K_{a}$ of boric acid is variable, the $\mathrm{pH}$ of the equivalence point and inflection point will be dependent on the concentration of mannitol in the solution as well as on the concentration of the salt at the equivalence point. The variable $p K_{\text {" }}$ could be considered essentially unique for this system since the number of acids which can vary their $p K$ in aqueous medium by addition of virtually inert reagent in the acid-base hydrolytic respect is rather limited. On the other hand, the change in $(\mathrm{pH})_{\text {equiv }}$ with concentration of the salt produced as a result of neutralization reaction is, of course, inherent to titration of any weak acid.

The discouragement of Colman and Rigdon [21] with unavailability of standard boric acid and difficulty of preparing material of known stoichiometry need not be the deterrent now to those interested in boron chemistry since virtually stoichiometric SRM boric acid of known $B_{10} / B_{11}$ ratio is now issued by the National Bureau of Standards [27].

The evaluation of possible suspected sources of systematic error in these determinations revealed no bias in the newly developed method. The precision of the method, expressed as a standard deviation of a single determination is 0.0033 percent. It can therefore be inferred that the discrepancy found by Le Duigou and Lauer between coulometric and conventional acidimetry of boric acid does not have its origin in coulometric titration, and is apparently not inherent to this system, since our investigations were conducted under conditions which were similar to those used by these authors [7].

The developed method expands further the repertoire of the available precise and accurate methods of analysis and permits the assay of standard reference materials on the absolute basis thus reducing the possibility of propagation of errors.

The developed high precision method enables one to study and systematize the small changes in the composition of material as a function of various changes in the environment with the minimum number of titrations. The developed method served as the starting point for the development of a precise method for the analysis of micro samples of separated boron isotopes, which shall be described elsewhere.

\section{Conclusions}

A coulometric method of high precision and accuracy has been developed for assaying boric acid. The imprecision of the method, expressed as a standard deviation of a single determination, is 0.0033 percent. The evaluation of all known possible sources of systematic error in these determinations suggest that the method is bias free. 
The method expands further the inventory of precise and accurate methods of analysis and permits assay of standard reference materials on the absolute basis, thus reducing the propagation of errors which is innate to multistage comparison methods.

The authors are indebted to W. V. Loebenstein, J. Filliben, and B. L. Joiner, of the National Bureau of Standards, for statistical analysis and helpful suggestions in the preparation of this manuscript.

\section{References}

[1] Taylor, J. K., and Smith, S. W., J. Res. Nat. Bur. Stand. (U.S.), 63A (Phys. and Chem.), No. 2, 153 (1959).

[2] Marinenko, G., and Taylor, J. K., J. Res. Nat. Bur. Stand. (U.S.), 67A (Phys. and Chem.), No. 1, 31 (1963).

[3] Marinenko, G., and Taylor, J. K., J. Res. Nat. Bur. Stand. (U.S.), 67A (Phys. and Chem.), No. 5, 453 (1963).

[4] Taylor, J. K., and Marinenko, G., Proc. Conf. High-Precision Analysis of Substances of Interest to Nuclear Energy, Bureau Central de Mesures Nucleaires, pp. 147-161 (Brussels, Belgium 1965).

[5] Marinenko, G., and Taylor, J. K., Anal. Chem. 39, 1568 (1967)

[6] Wilson, C. L., and Wilson, D. W., Ed., Comprehensive Analytical Chemistry, Ic, pp. 89-102 (Elsevier Publishing Co., London, 1962).
[7] Le Duigou, Y., and Lauer, K. F., Proc. Conf. High-Precision Analysis of Substances of Interest to Nuclear Energy, Bureau Central de Mesures Nucleaires (Brussels, Belgium 1965).

[8] Marinenko, G., and Taylor, J. K., Anal. Chem. 40, 1645 (1968).

[9] Marinenko, G., and Champion, C. E., Anal. Chem. 41, 1208 (1969).

[10] Roller, P. S., J. Am. Chem. Soc. 50, 1 (1928).

[11] Eckfeldt, E. L., and Shaffer, E. W.. Anal. Chem. 37, 1534 (1965).

[12] Taylor, J. K., Ed., Nat. Bur. Stand. (U.S.), Tech. Note 425, 52 (1967).

[13] Torgesen, J. L., and Strassburger, J., Science 146, 53 (1964).

[14] Taylor, J. K., Ed., Nat. Bur. Stand. (U.S.), Tech. Note 400, 78 (1966).

[15] Hildebrand, J. H., J. Am. Chem. Soc. 35, 860 (1913).

[16] van Liempt, J. A. M., Z. anorg. Chem. 111 , 151 (1920).

[17] Magnanini, G., Z. physikal. Chem. 6, 58 (1890).

[18] Schafer, H., Z. anorg. allgem. Chem. 247, 97 (1941).

[19] Deutsch, A. and Osling, S., J. Am. Chem. Soc. 71, 1637 (1949).

[20] Ross, S. D., and Catotti, A. J., J. Am. Chem. Soc. 71, 3563 (1949).

[21] Colman, D. M., and Rigdon, L. P., U.S. Atomic Energy Comm. Rept. UCRL 7756 (1964).

[22] Le Duigou, Y., and Lauer, K. F., Anal. Chim. Acta 33, 222 (1965).

[23] Mandel, J., The Statistical Analysis of Experimental Data, pp. 185-192 (Interscience Publishers, New York, 1964).

[24] Cooper, F. A., and Quayle, J. C., Analyst 91, 363 (1966).

[25] Goode, G. C., Herrington, J., and Jones, W. T., Anal. Chim. Acta 37, 445 (1967).

[26] Knoeck, J., and Taylor, J. K., Anal. Chem. 41, 1730 (1969).

[27] Nat. Bur. Stand. (U.S.), Tech. News Bull. 52, No. 12, 282 (1968).

(Paper 75A5-675) 